\title{
AN ONTOLOGY-BASED KNOWLEDGE MANAGEMENT FRAMEWORK FOR PERFORMANCE IMPROVEMENT OF CONSTRUCTION PROJECT MANAGERS
}

\author{
V. Paul Christopher Charlesraj \\ Ph.D Scholar \\ Satyanarayana N. Kalidindi \\ Professor \\ Building Technology and Construction Management Division \\ Department of Civil Engineering \\ Indian Institute of Technology Madras \\ Chennai 600036 India \\ paul@iitm.ac.in_satyakn@iitm.ac.in
}

\begin{abstract}
Knowledge Management' (KM) is a promising business management concept that is gaining wide acceptance and is being implemented in various sectors to achieve improved level of performance and competence. Project management competence is one of the most significant criteria upon which the project performance is dependent on. Further, effective project management relies on the project manager's competency and authority. Construction Project Managers (CPManagers) play a key role in the success of a construction project. Assessment and improvement of the Skill, Knowledge, and Competency (SKC) levels of CPManagers will be valuable to CPManagers as well as the organisation. Selection and allocation of suitable CPManagers to projects is a challenging issue. An ontology-based KM framework for performance improvement of CPManagers has been proposed. Ontology of SKC of CPManagers, Construction Projects, and $\mathrm{KM}$ Tools constitute the knowledge component. Various elements of competence that are required for CPManagers have been identified.
\end{abstract}

Keywords: Project manager, Performance improvement, Knowledge management, Ontology.

\section{INTRODUCTION}

With the construction industry becoming more information and knowledge intensive, it has become essential for construction organisations to manage the knowledge embedded in the construction business processes to remain competitive. 'Knowledge Management' $(\mathrm{KM})$ is a promising business management concept that is gaining wide acceptance and is being implemented in various sectors to achieve improved level of performance.

Project management competence is one of the most significant criteria upon which the project performance is dependent on. Further, effective project management relies on the project manager's competency and authority. Construction Project Managers (CPManagers) play a key role in the success of a construction project. They are one of the important knowledge resources in a construction organisation. Assessment and improvement of the Skill, Knowledge, and Competency (SKC) levels of CPManagers will be valuable to CPManagers as well as the organisation.

Selection and allocation of suitable CPManagers to projects is a challenging issue. The SKC of a perfect CPManager for a given project has to be defined based on project characteristics and environmental variables. The CPManagers having SKC close to the defined target level also have to be identified. This requires a systematic procedure for the assessment of SKC levels of available CPManagers. A hybrid approach that combines the assessment of personal qualities (input-oriented; macro-level; person-oriented) as well as the functional analysis (output-oriented; micro-level; task-oriented) is appropriate for the realistic assessment. The objective of this paper is to present the proposed conceptual model, which is an ontology-based KM framework for performance improvement of CPManagers.

\section{LITERATURE REVIEW}

A brief review of literature related to the role of CPManagers in the performance of construction projects, competency development of project managers, KM in construction, and ontologies in KM systems is presented in this section.

\subsection{Construction Project Performance - Role of CPManagers}

Various attempts have been made by researchers to identify critical success factors (CSF) in construction. A review related to CSFs in construction revealed that a number of variables influencing project success can be grouped under five main categories, viz., human-related factors, project-related factors, project procedures, project management actions, and external environment [1]. To achieve a successful project delivery the project manager should fulfill a number of roles including those of facilitator, coordinator, motivator, and politician. However, the review of literature suggests that attention paid to the development of appropriate performance measures for project managers is marginal [2]. 


\subsection{Competency Development of Project Managers}

There are two main approaches for the assessment of competency of managers, one originated from USA and the other from UK [3],[4]. The former approach deals with the personal qualities of the managers that means input-oriented and a macro level approach. The UK-originated approach is task-oriented (output-oriented) involving functional analysis at micro level. Both the approaches are complementary to each other. The Project Management Institute (PMI) has come up with a generic framework for competency development of project managers [5]. Several factors influencing the performance of CPManagers were reported [2],[6],[7],[8]. There is a need for a holistic approach for the performance framework of project managers [9].

\section{$2.3 \mathrm{KM}$ in Construction}

The applicability and usefulness of KM in construction has been researched in strategic management of construction [10], general construction project management [11],[12], knowledge discovery from construction databases [13] and corporate memory for construction [14].

\subsection{Ontologies and KM Systems}

Ontology is an explicit specification of a conceptualisation [15]. Maedche et al. [16] proposed integrated enterprise-KM architecture for implementing an Ontology-based KM System (OKMS). Distributed ontology architecture for KM in highway construction has been proposed by El-Diraby \& Kashif [17].

The research efforts in the field of KM in construction are limited. With KM showing promise to improve the organisational performance and limited attention paid to the development of appropriate system for performance measure of CPManagers, there is a need for investigating the role of $\mathrm{KM}$ in the performance improvement of the CPManagers.

\section{FRAMEWORK DESCRIPTION}

The concept map that illustrates the proposed ontology-based KM framework for performance improvement of CPManagers is presented in Figure 1. The ontology of SKC of CPManagers, Construction Projects, and KM Tools constitute the knowledge component. These ontologies represent the body of knowledge in their respective domains. They also turn out to be the standard vocabulary that makes possible a common understanding among the personnel in the organisation, which prevent ambiguity.

The objective is to identify the CPManager with right SKC for the project at hand. It involves the assessment of the SKC of the available CPManagers as well as defining the target SKC to successfully manage the project in hand. By mapping the current SKC level to the target SKC (which has been arrived at based on the project specifications,

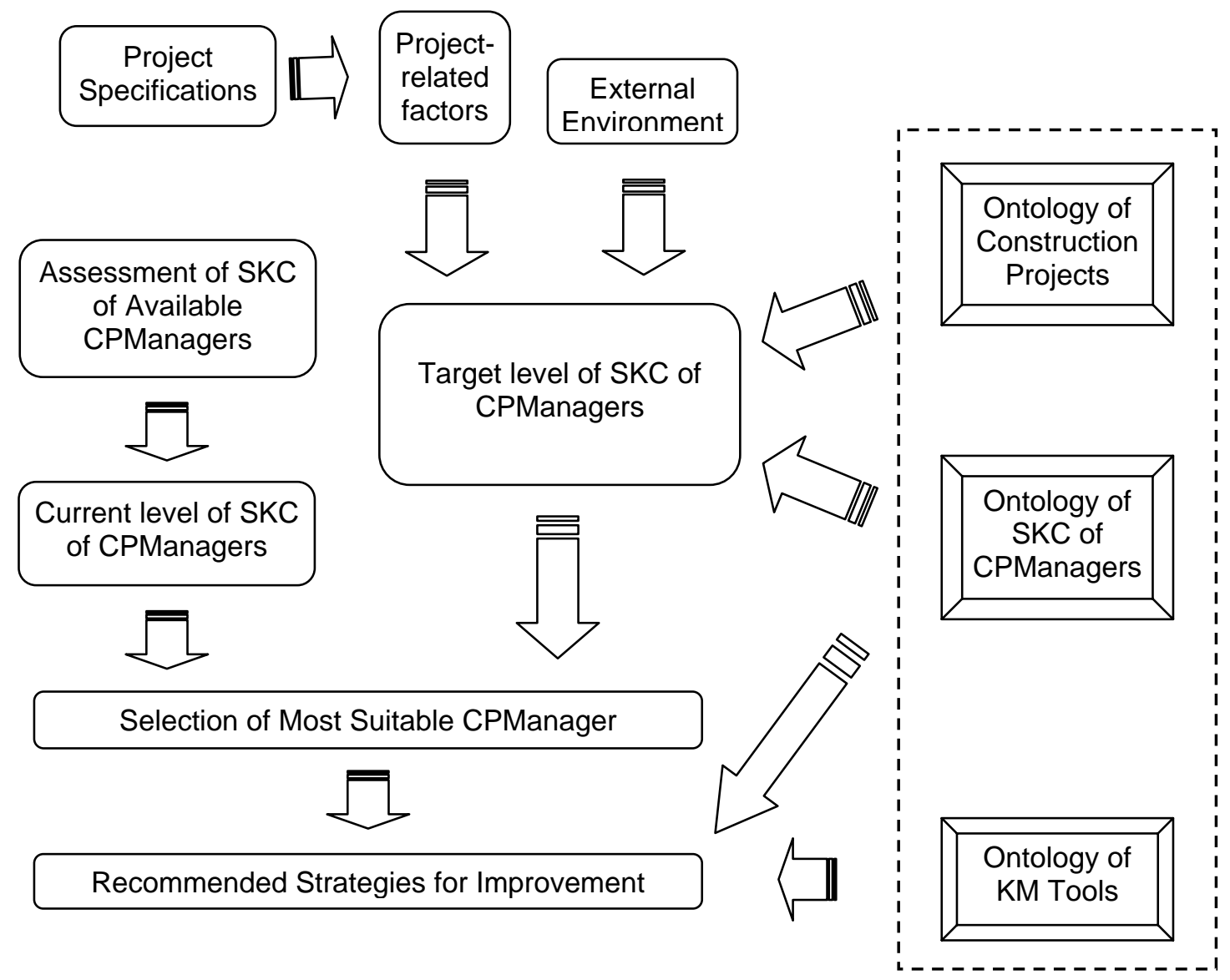

Figure 1. Concept Map of Proposed Framework 
external environment and the ontology of SKC of CPManagers) one can select the CPManager with the best possible combinations of SKC required to successfully complete the project. As it is near impossible to identify the ideal CPManager for a given project, it is possible to enhance the SKC level of the best CPManager among those available through KM.

\subsection{Elements of Competence for CPManagers}

The elements of competence required for CPManagers have been identified using the PMI's framework for competency development of project managers [5] as the basis. To be recognized as fully competent, an individual would need to be evaluated successfully against each of the following three dimensions:

a) Project Management Knowledge - The knowledge and understanding that a project manager bring to a project or project-related activity (The knowledge component of competence)

b) Project Management Performance - The ability of individual project managers to perform project management activities to the levels of performance expected

c) Personal Competency - The core personality characteristics underlying a person's capability to do a project or project activity.

Project management competence elements (61 nos. given in Appendix A) have been identified and organized into nine units of competence, which are nine knowledge areas of project management as defined in PMBOK (Project Management Body of Knowledge) [18]. The nine project management knowledge areas are:

(i) Project Integration Management

(ii) Project Scope Management

(iii) Project Time Management

(iv) Project Cost Management

(v) Project Quality Management

(vi) Project Human Resources Management

(vii) Project Communications Management

(viii) Project Risk Management

(ix) Project Procurement Management

They are also grouped under five clusters of competence based on the five project management process groups (viz. Initiating, Planning, Executing, Controlling and Closing).

Personal competence elements (40 nos. given in Appendix B) have been identified and grouped under six units of competence, namely, (i) Achievement and Action, (ii) Helping and Human Service, (iii) Impact and Influence, (iv) Managerial, (v) Cognitive, and (vi) Personal Effectiveness. They are also organized under 2 to 4 clusters per unit.

Each of these competency elements have been identified with a set of attributes, namely, ElementID, Unit of Competence, Cluster of Competence, Performance Criteria, and Assessment Guidelines. A snapshot of the structure of a competency element is shown in Figure 2 as implemented in Protégé [19].

\subsection{Ontology of KM Tools}

Similarly, a list of KM tools has been identified. They are classified as KM Technologies and KM Techniques based on the use of Information \& Communication Technology (ICT). ICT-based tools are classified as KM Technologies and the non-ICT-based tools as KM Techniques. The KM sub-processes (Locate, Capture, Represent, Share, and Create), where these tools are applicable and the knowledge domains (Transfer, Ownership and Conversion) they belong to were identified. A knowledge mapping of current-desired state of these three domains, Transfer (Internal/External), Ownership (Individual/Group) and Conversion (Implicit/Explicit) has been done. This mapping will be helpful in deciding on the strategies for improving current SKC level to target level. The ontology of the KM Tools has been implemented using Protégé [19]. The class hierarchy of the KM Tools ontology can be found in Figure 3.

The ontology of the KM Tools defines and describes various KM tools that can be adopted in different contexts to achieve specific KM objectives. It forms the knowledgebase of the proposed KMS prototype along with the ontology of SKC of CPManagers. It has been proposed to define the target level of SKC of CPManagers by considering the current project characteristics and the external environment. The factors to be considered have been identified. The ontology of SKC of CPManagers will facilitate this process.

\subsection{Competency Assessment of CPManagers}

An approach for the 360 degree evaluation and assessment of project management as well as personal competency of CPManagers is being developed. It is being developed as a hybrid approach of USA and UK-based approaches as discussed in the literature review.

It has been proposed to define the target level of SKC of CPManagers by considering the current project characteristics and the external environment. The factors to be considered have been identified. The ontology of SKC of CPManagers and ontology of Construction Projects will facilitate this process. An algorithm is to be proposed for recommending $\mathrm{KM}$ strategies for improvement of performance of CPManagers based on current \& target level of competence with the aid of ontology of SKC and KM tools.

The implementation of the proposed ontology-based $\mathrm{KM}$ framework is an ongoing project. A pilot survey shall be conducted to refine and finalise the elements of competence. Behaviourial Event Interviews shall be conducted for the assessment of SKC of CPManagers. The entire framework will be tested using case study approach. 


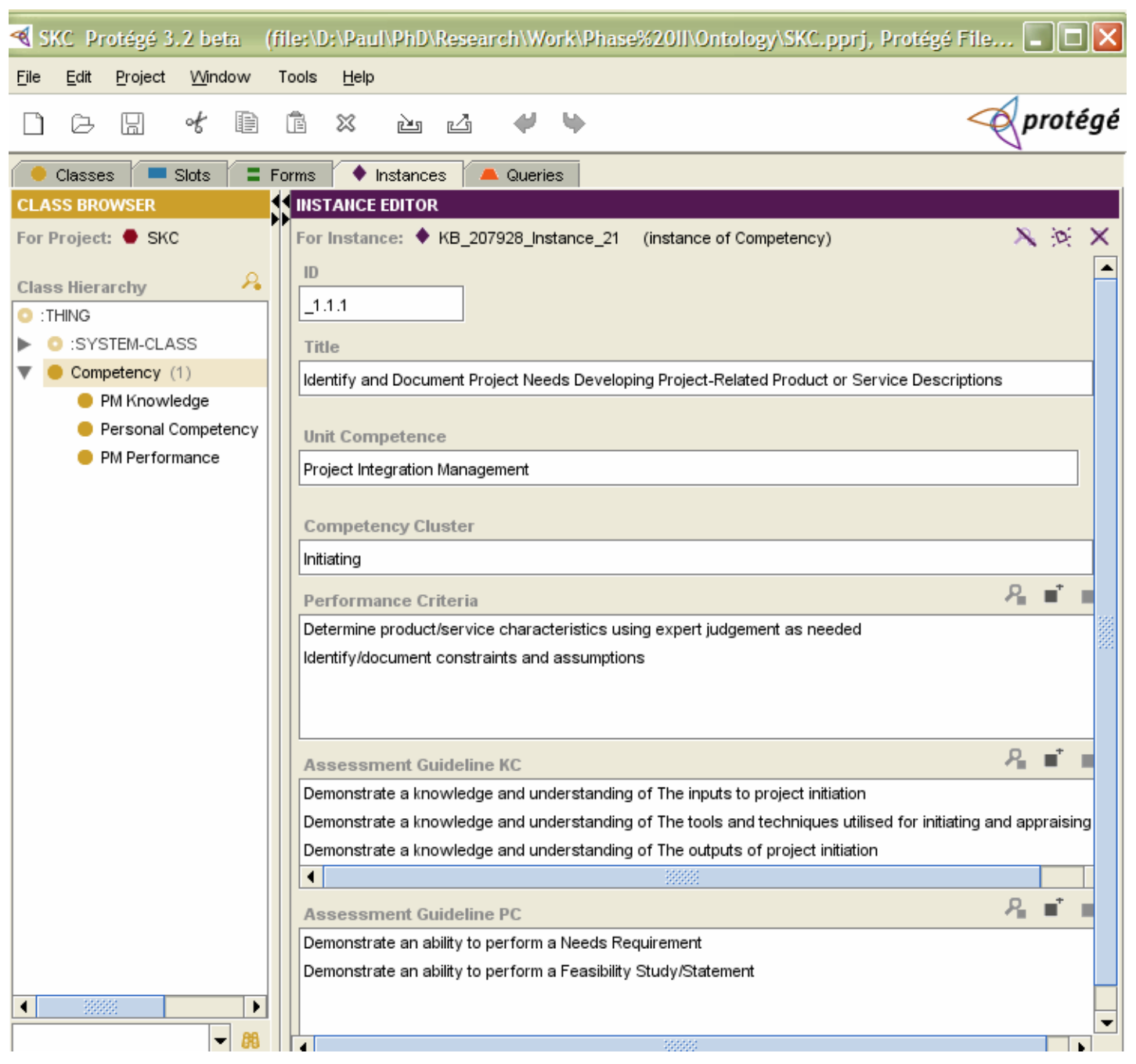

Figure 2 Sample Element of Competence

\section{SUMMARY}

Selection and allocation of suitable CPManagers to projects is a challenging issue. An ontology-based KM framework has been presented for the performance improvement of CPManagers. Implementation of this framework in a construction organisation can improve the effectiveness \& efficiency of the CPManagers and also it provides a solid platform for recruitment, training, self-learning and personal career development of CPManagers.

\section{REFERENCES}

[1] Chan, A. P. C., Scott, D. and Chan, P. L. (2004). "Factors affecting the success of a construction project.” ASCE Journal of Construction Engineering and Management, 130(1), 153-155.

[2] Dainty, A. R. J., Cheng, M. and Moore, D. R. (2003). "Redefining performance measures for construction project managers: an empirical evaluation." Construction Management and Economics, 21(2), 209-218.
[3] Cheng, M., Dainty, A. R. J. and Moore, D. R. (2003). "The differing faces of managerial competency in Britain and America." The Journal of Management Development, 22(6), 527-537.

[4] Dainty, A. R. J., Cheng, M. and Moore, D. R. (2005). "Competency-based model for predicting construction project managers' performance.” ASCE Journal of Management in Engineering, 21(1), 2-9.

[5] PMI (Project Management Institute) (2002). "Project management competency development framework." Project Management Institute, Pennsylvania, USA.

[6] Dainty, A. R. J., Cheng, M. and Moore, D. R. (2004). "A competency-based performance model for construction project managers." Construction Management and Economics, 22(8), 877-886.

[7] Egbu, C. O. (1999). "Skills, knowledge and competencies for managing construction refurbishing works." Construction Management and Economics, 17(1), 29-43.

[8] Edum-Fotwe, F. T. and McCaffer, R. (2000). "Developing project management competency: perspectives from the construction industry." 


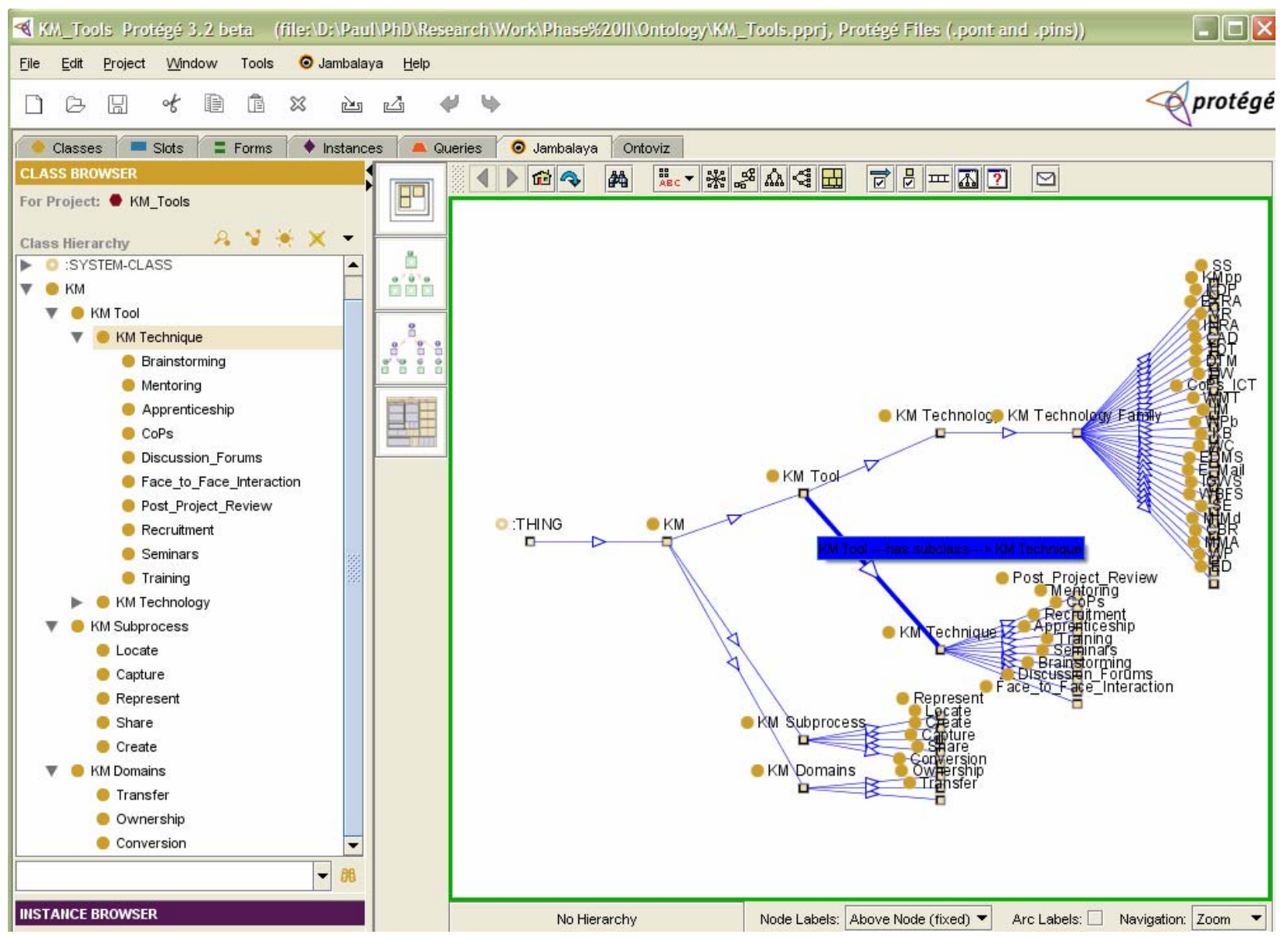

Figure 3 Class Hierarchy in KM Tools Ontology

International Journal of Project Management, 18, 111-124.

[9] Cheng, M.-I., Dainty, A.R.J., and Moore, D.R. (2005). "Towards a multidimensional competency-based managerial performance framework: A hybrid approach.” Journal of Managerial Psychology, 20 (5), 380-396.

[10] Carrillo, P. M., Robinson, H. S., Anumba, C. J. and Al-Ghassani, A. M. (2003). "IMPaKT: A framework for linking knowledge management to business performance." Electronic Journal of Knowledge Management, 1(1), 1-12.

[11] Whelton, M., Ballard, G., and Tommelein, I. D. (2002). "A knowledge management framework for project definition." Electronic Journal of Information Technology in Construction, ITCON, 7, 197-212.

[12] Wetherill, M., Rezgui, Y., Lima, C., and Zarli, A. (2002). "Knowledge management for the construction industry: The e-COGNOS project.” Electronic Journal of Information Technology in Construction, ITCON, 7, 183-196.

[13] O’Brien, W. J., Issa, R. R. A. Hammer, J., Schmalz, M. S., Geunes, J. and Bai, S. X. (2002). "SEEK: Accomplishing enterprise information integration across heterogeneous sources.” Electronic Journal of
Information Technology in Construction, ITCON, 7, 101-124.

[14] Ribeiro, F. L. (2000). "Toward a technology for corporate memories in construction.” Proceedings of the International conference of CIB W78 on Construction Information Technology 2000, Reykjavik, Iceland, 28-30 June.

[15] Gruber, T. (1993). “A translation approach to portable ontologies.” Knowledge Acquisition, 5(2), 199-220.

[16] Maedche, A., Motik, B., Stojanovic, L., Studer, R. and Volz, R. (2003). “Ontologies for enterprise knowledge management.” IEEE Intelligent Systems, 18(2), 26-33.

[17] El-Diraby, and Kashif, K. F. (2005). "Distributed ontology architecture for knowledge management in highway construction.” ASCE Journal of Construction Engineering and Management, 131(5), 591-603.

[18] PMI (Project Management Institute) (2000). “A Guide to the Project Management Body of Knowledge (PMBOK Guide) - 2000 edition.” Project Management Institute, Pennsylvania, USA.

[19] The Protégé (2006). “The Protégé; Ontology Editor and Knowledge Acquisition System.” $<$ http://protege.stanford.edu>, last visited 24 Feb 2006.

\section{Appendix A}




\section{Elements of Project Management Competence}

1. Identify and document project needs developing project-related product or service descriptions

2. Perform an initial project feasibility study and analysis

3. Conduct project plan development

4. Conduct project plan execution

5. Conduct integrated change control

6. Conduct project closure with regard to integration

7. Prepare project charter

8. Conduct scope planning

9. Conduct scope definition

10. Execute scope

11. Conduct scope verification

12. Conduct scope change control

13. Conduct Project closure with regard to scope

14. Preliminary planning activities

15. Conduct activity definition

16. Conduct activity sequencing

17. Conduct activity duration estimation

18. Conduct schedule development

19. Implement project schedule

20. Conduct schedule control

21. Conduct project closure with regard to time

22. High-level budget development preparation

23. Conduct resource planning

24. Conduct cost estimating

25. Conduct cost budgeting

26. Execute cost baseline

27. Conduct cost control

28. Conduct project closure with regard to cost

29. Determine quality requirements

30. Conduct quality planning

31. Conduct quality assurance

32. Conduct quality control

33. Conduct project closure with regard to quality

34. Conduct organisational definition

35. Conduct organisational planning

36. Conduct staff acquisition

37. Conduct team development

38. Manage HR

39. Conduct project closure with regard to HRM

40. Preliminary communications planning

41. Conduct communications planning

42. Conduct information distribution

43. Conduct project performance reporting

44. Conduct administrative closeout

45. Conduct preliminary risk planning

46. Develop risk management plan

47. Conduct risk identification

48. Conduct qualitative risk analysis

49. Conduct quantitative risk analysis

50. Conduct risk response planning

51. Execute risk response plan

52. Conduct risk monitoring and control

53. Conduct project closure with regard to RM

54. Preliminary procurement planning

55. Conduct procurement planning

56. Conduct solicitation process

57. Conduct solicitation
58. Conduct source selection/contract development

59. Conduct contract administration

60. Manage and review contract performance

61. Conduct contract closeout

\section{Appendix B}

\section{Elements of Personal Competence}

1. Operates with intensity to achieve project goals

2. Motivates project stakeholders in a positive way

3. Provides new solutions in planning and developing strategies

4. Operates with individual integrity and personal professionalism

5. Manages projects in an ordered, accurate way

6. Provides accurate and truthful information

7. Takes initiative when required

8. Takes accountability for and delivers project

9. Seeks new opportunities

10. Strives for best practice

11. Ensures information used to manage project is complete and accurate

12. Represents the client inside the project

13. Takes initiatives to provide excellent client service

14. Strives to understand all project stakeholders' thoughts, feelings, and concerns

15. Listens and responds to others

16. Takes appropriate actions to influence others

17. Influences across projects and organisations

18. Understands and influences project team members

19. Understands the organisation

20. Understands the project

21. Builds and maintains suitable relationships with project stakeholders

22. Establishes and maintains at the right level inside and outside the organisations

23. Builds team orientation within the project

24. Molds core project stakeholders into a team

25. Undertakes team-building activities

26. Builds a project culture where personal development is encouraged

27. Develops project members to effectively build project culture

28. Demonstrates leadership of the project

29. Leads the project team

30. Uses assertiveness when necessary

31. Manages the complete project

32. Understands at a suitable level all issues associated with the project

33. Facilitates solutions across all issues related to the project

34. Sees the project in a holistic way

35. Maintains self-control

36. Creates an environment of confidence

37. Accepts failure positively

38. Changes to meet the needs of the project

39. Changes at the require pace

40. Demonstrates commitment to the project 